\title{
Model Studies on Heterogeneous Catalysts at the Atomic Scale: From Supported Metal Particles to Two-dimensional Zeolites
}

Hans-Joachim Freund, Markus Heyde, Niklas Nilius, Swetlana Schauermann, Shamil Shaikhutdinov, Martin Sterrer

Fritz-Haber Institut der Max-Planck Gesellschaft, Faradayweg 4-6, 14195 Berlin, Germany, +49 308413 4100, freund@fhi-berlin.mpg.de

\section{Keywords}

Model Systems, Dopants, Charge Transfer, Supported Nano Particles

\section{Abstract}

After a general introduction to model studies in catalysis, results from different research areas are presented: a) adsorption and reaction on nano particles supported on thin oxide films. It is shown that carbonaceous deposits on specific nano particle sites influence hydrogenation reactions through control of hydrogen surface-subsurface diffusion. b) 2D-3Dmorphology, geometric, and electronic structure of supported metal nano particles partially in relation to doping of the support. We learn how dopants, as electron sources, even if they are well beneath the active surface influence nano particle morphology on surfaces. c) strong metal-support interaction (SMSI). Ultrathin oxide films are proven to become chemically active in $\mathrm{CO}$ oxidation as they form on deposited nano particles dependent on the oxygen chemical potential in the gas phase. d) adsorption and reaction on two-dimensional silicates and alumino-silicates in ordered and vitreous phases. Bilayer silica films on Ru(0001) are transformed by $\mathrm{Al}$ doping into 2D-aluminum silicates and shown to exhibit binding hydroxyl with an acidity close to 3D-zeolites, such as chabazite for example.

\section{Table of Content}

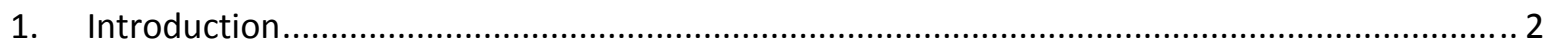

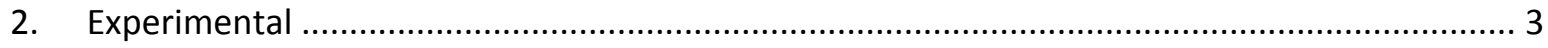

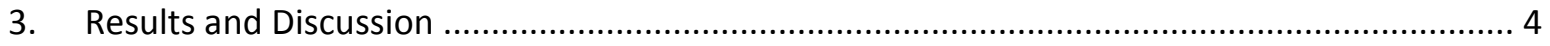

3.1. Carbon Deposits on supported Pd nano particles and its flexibility ................................. 4

3.2. Reactivity of supported flat Au nano particles ................................................................... 7

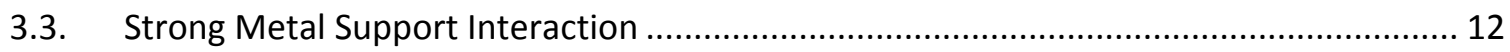

3.4. Two-dimensional silica and alumino-silicates towards a surface science of zeolites ....... 14 
4. Conclusion and outlook

5. Acknowledgment.

\section{Introduction}

Heterogeneous catalysts are complex materials consisting of combinations of different components, such as an oxide support and an active disperse metal. The classical model system for these materials, in the past, has been the metal single crystal [1-3]. The reason for this choice can be made transparent by inspecting Figure 1 [4]. It shows STM images of Pd nano particles, which were grown by physical vapor deposition of Pd onto a thin alumina film. The left image showing a larger area reveals the presence of nanoscopic Pd single crystals exposing well defined facets. The image at atomic resolution supports the idea that the topmost facet, indeed exhibits (111) morphology and structure. Exactly those observations, made in the 60ies of the last century, at the time with transmission electron microscopy [1], were the basis for the development of single crystal model systems of defined orientation within surface science, in order to understand the elementary steps of chemical reactions at surfaces $[5,6]$. Our understanding of catalysis, and heterogeneous catalysis, in particular, is, to a large extent, based on these investigations of model systems. The enormous impact of metal single crystal model surface chemistry, pioneered by physical chemists that led to the 2007 Nobel Prize in chemistry for Gerhard Ertl, has been the basis for an outstanding success story [6]. The simplicity of this model approach is particularly appealing, and it is this aspect that has led to some of the groundbreaking ideas influencing our thinking about catalytic reactions. However, it is also very obvious, that a full understanding of all factors influencing catalytic reactions requires a considerable increase of complexity in the structure and morphology of the model systems, actually, taking the finite size of the disperse metal particles and the support-metal interface into account $[7,8]$. The important question is: how much complexity is necessary to catch the relevant aspects [9]. It is obvious, however, that the only strategy that will lead to an understanding at the atomic level is to proceed from the simple to the complex and not the other way around!

We have developed concepts to prepare more complex model systems based on single crystalline oxide films, which are used as supports for metal and oxide nano particles [10-13]. Together with the development of novel instrumentation [14], this approach allows us to 
study the factors influencing catalysis at the atomic level using the tools that have been developed, and so successfully applied, during the last thirty years in surface science, including those based on scanning probe techniques $[15,16]$.

Here, we report on different areas, where such an approach has allowed us to directly establish structure/morphology-reactivity relations previously impossible, and thus explain some surprising observations made in real catalysis. Using a model system similar to the one shown in Figure 1 we investigate the question, why one needs the presence of deposited carbon on nano particles to sustain hydrogenation catalysis in the conversion of alkenes to alkanes $[17,18]$, and how does this relate to the higher degree of flexibility of nano particles as compared to metal single crystals influencing the adsorption enthalpy of molecules [19, 20]. We address in a further case study the morphology and structure of nano particulate supported gold occurring as small, flat raft-like aggregates and the role of the oxide metal interface in relation to its unmatched reactivity in $\mathrm{CO}$ oxidation [21-23]. Then we pursue the study of charge transfer through oxide films as a function of their morphology and thickness to reveal novel mechanisms of molecular activation on oxides in the case of encapsulation of nano particles and strong metal support interaction (SMSI) [24]. In a final case study we reveal our initial experiments to prepare two-dimensional well-ordered silica and aluminosilica surfaces in an attempt to study the surface science of zeolites [25, 26].

\section{Experimental}

The experiments were carried out in a number of custom made ultrahigh vacuum (uhv) systems, including equipment to bring samples to ambient conditions with direct transfer. $A$ broad variety of experimental techniques have been applied [14]. These include scanning tunneling microscopy in uhv and ambient conditions, non-contact atomic force microscopy, elastic and inelastic electron scattering, photon-STM, infrared-Fourier-transform spectroscopy, non-linear optical techniques, electron spin resonance spectroscopy, resonant nuclear reaction analysis, molecular beam techniques, microcalorimetry and combinations thereof. The materials were prepared by epitaxial growth of oxides by reactive physical vapor deposition in uhv. Surface modifications and exposure to gases were carried out via specifically designed gas handling systems. 


\section{Results and Discussion}

\subsection{Carbon Deposits on supported Pd nano particles and its flexibility}

Figure 2 shows a comparison of hydrogenation rates of trans-2-butene to $d_{2}$-butane obtained from a series of pulsed molecular beam experiments, in which $\mathrm{Fe}_{3} \mathrm{O}_{4}(111)$ supported $\mathrm{Pd}$ nano particles of $4 \mathrm{~nm}$ average diameter (similar to the Pd particles on alumina imaged in Figure 1) were exposed to a continuous $D_{2}$ molecular beam and a modulated cis-2-butene (which was chosen as the model di-methyl substituted ethene) molecular beam at $260 \mathrm{~K}$ [17]. The figure shows the product response curves obtained for hydrogenation under steady state conditions in comparison with similar results on $\mathrm{Pd}(111)$. The rates were calculated by averaging the reaction rates from the last 30 long pulses of the experiment and were normalized to the number of the surface Pd atoms for quantitative comparison. Shown are the hydrogenation rates plotted as a function of time on $\mathrm{Pd}(111)$ (upper row) and $\mathrm{Pd}$ particles (lower row) on the C-free (black curves) and C-containing (grey curves) surfaces. It is noteworthy that on both C-free surfaces no sustained hydrogenation is observed $[17,18$, $27,28]$. Figure 3 shows the production rate of butane- $d_{2}$ resulting from the reaction of cis-2butene with $\mathrm{D}_{2}$ over a C-free (Figure $3 a$ ) and C-precovered (Figure $3 b$ ) Pd-supported model catalysts at $260 \mathrm{~K}$, which were pre-saturated with $D_{2}$ prior to the olefin exposure. A sequence of cis-2-butene pulses, consisting of 50 short ( $4 \mathrm{~s}$ on, $4 \mathrm{~s}$ off) and 30 long ( $20 \mathrm{~s}$ on, 10 s off) ones, was applied using an independent beam source concomitant with the continuous $D_{2}$ exposure. The reaction was carried out in a large excess of $D_{2}$ with the ratio of $D_{2}$ :cis-2butene molecules amounting to 570 . On the pristine Pd particles (Figure 3a), the initial period of high hydrogenation activity on D-saturated catalyst is followed by a decrease of the reaction rate to zero under steady-state conditions. Remarkably, carbon deposition prevents the suppression of the hydrogenation pathway in the steady state and results in persisting hydrogenation activity at the initially high level (Figure 3b). It should be noted that the reaction rate of the cis-trans isomerization/H-D exchange, i.e. the reaction competing with hydrogenation, according to the Horiuti-Polanyi mechanism [29], in the steady state remains very similar on both $\mathrm{C}$-free and C-precovered Pd particles, indicating that the surface concentrations of $D$ and butyl- $d_{1}$ are not substantially affected by $C$ deposition under the investigated conditions. The microscopic reasons for the vanishing hydrogenation activity on the C-free catalyst could be deduced recently from the combination of $\mathrm{H}$-depth profiling nuclear 
reaction analysis (NRA) measurements and transient molecular beam experiments [26, 30] carried out at different $\mathrm{H}_{2} / \mathrm{D}_{2}$ pressures [18], which provided experimental evidence that the presence of subsurface $\mathrm{H}$ species [30] is necessary for hydrogenation. In view of this finding, the initially high hydrogenation rate (probed by the initial short pulses) on both C-free and Cprecovered Pd particles can be ascribed to the high availability of subsurface $D$ atoms directly after pre-saturation. However, the abundance of these species on the C-free particles cannot be maintained at the initially high level after prolonged olefin exposure, resulting in vanishing hydrogenation rates. This behavior was suggested [18] to be a consequence of the slow D subsurface diffusion hindered by co-adsorbed hydrocarbons. In contrast, sustained hydrogenation activity of the C-precovered particles indicates effective replenishment of the subsurface D species even under steady state reaction conditions. It is possible that hydrogen subsurface diffusion through the C-modified edge sites can be the reason for this observation, as was recently supported by theoretical calculations [31]. Summarizing, we find, that due to the considerably higher flexibility of the more or less strained lattice of the supported small particle as compared with a single crystal, and due to the size of the object, the interior of the particle actively participates in hydrogenation reactions, by hydrogen accommodation at conditions different from the bulk material. Although the important role of carbonaceous deposits in the activity and selectivity of transition metals has been recognized for a long time in the catalytic community, [32-34] it only via such model studies that one reaches an understanding at the atomic level. On single crystals the deposition of several well defined carbonaceous species, among them ethylidyne, have been identified $[35,36]$ but they have been merely considered to be spectators blocking sites: Now we know that such dehydrogenated hydrocarbon derivatives may fulfill different functions on appropriate systems. While hydrogenation is an example for the influence of flexibility under reaction conditions, there are more subtle effects for nano particles, which already show up for relatively large supported nanoparticles of $4-8 \mathrm{~nm}$ in adsorption experiments, i.e. the variation of the adsorption enthalphy with particle size in comparison with single crystals [19]. In order to study such subtle effects one cannot use temperature programmed desorption techniques - the otherwise typically applied techniques in surface science to determine adsorption energies - because, during heating, the supported particles undergo considerable changes. The method of choice in this situation is single crystal adsorption calorimetry (SCAC). This technique, described in detail elsewhere $[37,38]$ allows one to determine ad- 
sorption enthalpies of molecular adsorption as well as dissociative adsorption in a thermodynamically profound fashion on a small area single crystal based sample. The experiments summarized in the following have been conducted on the same kind of model systems used in the reactivity studies discussed above $[20,38]$. To address the dependence of the initial 0 adsorption energies on particle size in more detail [20], for example, four different supported model systems with different Pd particle sizes ranging from $\sim 2 \mathrm{~nm}$ to $\sim 8 \mathrm{~nm}$ were investigated by SCAC. The initial heats of adsorption on all supported systems are displayed in Figure $4 \mathrm{~d}$ as a function of the nominal Pd deposition thickness together with data measured on $\mathrm{Pd}(111)$. Each point in this curve represents an average of 4 to 6 independent measurements on freshly prepared model systems. The dependence of the $\mathrm{O}$ adsorption energy on the particle size shows a clear trend: it strongly rises from $\sim 205 \mathrm{~kJ} \cdot \mathrm{mol}-1$ to $250-275 \mathrm{~kJ} \cdot \mathrm{mol}-1$ when changing from $\mathrm{Pd}(111)$, where oxygen adsorbs at threefold-hollow sites, to large Pd nanoclusters, where oxygen first occupies particles edges, as evidenced by IRAS data, which have been shown elsewhere [20]. However, if the local adsorption site (the edge/corner site) was preserved, and only the particles size was reduced, the initial oxygen adsorption energy was observed to strongly decrease, reaching the value of $205 \mathrm{~kJ} \cdot \mathrm{mol}-1$ on the smallest Pd nano particles. Thus, the reduction of the Pd cluster size results in an opposite trend - decrease of the adsorption energy - with the magnitude that is comparable with the effect of the change of the local adsorption environment. Note that the total number of oxygen atoms, contributing to the initial adsorption energies (on the pristine Pd nano particles) reported in Figure 4a, amounts typically to only a few $\mathrm{O}$ atoms per particle or less than 0.04 per surface $\mathrm{Pd}$ atom. Since the number of surface $\mathrm{Pd}$ atoms on each particle is much larger ( 140 on the smallest and 1100 on the largest Pd clusters) than the number of adsorbed 0 atoms, we can safely assume that the repulsive interaction between adsorbed $\mathrm{O}$ atoms do not play any significant role for these low oxygen surface coverages. The latter trend - decreasing adsorption energy with decreasing particle size-coincides with the trend previously observed in our studies for $\mathrm{CO}$ adsorption in direct calorimetric experiments on the same model system [19]. The initial CO adsorption energy on the same Pd nano particles is plotted in Figure 4b for comparison, showing a pronounced decrease of the adsorption energy for small clusters. In contrast, the change of the adsorption site from a three-fold hollow on $\mathrm{Pd}(111)$ to the strongest binding site on Pd nano particles obviously does not result in an increase of the adsorption energy as observed for oxygen. This observation agrees well with 
literature data, suggesting that the degree of coordination of the surface $\mathrm{Pd}$ atoms both on low Miller index surfaces and on stepped Pd surfaces does not significantly affect the CO binding energy (for the full discussion see Ref. [39]).

Two alternative microscopic effects can be put forward to rationalize the observed decrease of the initial adsorption energy on $\mathrm{Pd}$ nano particles both for oxygen and $\mathrm{CO}$ adsorption: weakening of the chemisorptive interaction [40-46] and reduction of the van-der-Waals attraction $[47,48]$. The decrease of the chemisorption energy has been previously predicted in a theoretical study for Pd clusters [40-42] in the size range corresponding to a scalable regime. These computational results showed that interatomic Pd-Pd bond length in small metal particles decreases [49] with decreasing particle size and this effect results in systematically lower adsorption energies than on the clusters with a bulk terminated geometry, i.e. with all interatomic distances $d(P d-P d)=275 \mathrm{pm}$. This finding agrees well with the principle of bond order conservation $[45,46]$ : in the bond-contracted particles, one expects weaker adsorption bonds due to stronger binding within the particle. A second reason for the decrease of adsorption energy of a gas-phase molecule on the small metal clusters is a weakening of the van-der-Waals interaction strength $[47,48]$. This type of interaction is induced by the dynamic response of bulk electrons of the metal to charge density fluctuations in an adsorbed molecule, and since smaller clusters contain fewer electrons available for the dynamic response, the dispersive interaction strength weakens. This effect is expected to play a more important role for the interaction of $\mathrm{CO}$ with $\mathrm{Pd}$ clusters and be of minor importance in case of oxygen.

Via such studies one is forced to acknowledge that the flexibility of supported metal nano particles as a consequence of its limited size and the lattice strain induced through bonding to the support, results in complications for the description of adsorption and reaction at surfaces that need to be taken into account, also by theory, if one wants to be able to properly catch the details of a heterogeneous catalytic reaction.

\subsection{Reactivity of supported flat Au nano particles}

In the 80ies of the last century Masatake Haruta [50] discovered the high catalytic CO oxidation activity of Au nano particles anchored to a reducible support. The report initiated a very active search for the reasons of this unexpected discovery, as bulk Au is not exactly known 
for its chemical activity. The research group of the late Wayne Goodman [51] reported the first model studies on this system by preparing Au nano particles on a bulk $\mathrm{TiO}_{2}(110)$ surface and on thin $\mathrm{TiO}_{2}$ films and studying their relative $\mathrm{CO}$ oxidation activity. He compared flat raft like (two-dimensional) Au particles with three-dimensional or spherical particles and found that the latter were more than three times less active than the former. This turned out to be in line with observations using aberration-corrected TEM studies on $\mathrm{TiO}_{2}$ and $\mathrm{Fe}_{2} \mathrm{O}_{3}$ supported Au particles $[52,53]$ indicating that the most active particles exhibit a raft-like morphology and very limited size. On one hand those were very interesting observations, on the other hand, they also led to questions, such as: why would a metal aggregate, that usually exhibits three-dimensional morphology when grown on an oxide surface due to surface energetics (as in Figure 1 for Pd on alumina) in the case of Au grow two dimensional on an oxide substrate? A publication from the groups of Gianfranco Pacchioni and Uzi Landmann pointed towards a solution on the basis of a theoretical prediction $[54,55]$ : If one adsorbs a $\mathrm{Au}_{20}$ cluster (which Lei-Shang Wang showed to have the structure of an almost ideal tetrahedron having been cut out of a $\mathrm{Au}$ lattice [56] ) onto a $\mathrm{MgO}(100)$ surface, it keeps its threedimensional structure as expected based on total energy density functional calculations. If, however, one adsorbs the same moiety on a two layer thick $\mathrm{MgO}(100)$ film, supported on a Mo(100) metal surface, it prefers, based on the same calculations, to adopt a twodimensional, raft-like structure or in other words a monolayer island, while the threedimensional structure, stable on the bulk oxide, is higher in energy. As reason, the authors argue $[54,55]$ that electron transfer from the oxide-support-metal interface to the electronegative Au particle leads to this morphology, and it is the electron transfer that then induces the local wetting of the oxide. If this prediction were true we would have to look for sources of electrons within the support to induce the raft-like structure. We will come back to this after we have experimentally verified the above theoretical prediction.

In Figure 5, two sets of panels are depicted, each showing two STM images and a STM contour along the white lines indicated in the images [57-59]. The upper panel has been recorded for Au deposited from an evaporation source onto three layer thick $\mathrm{MgO}(100)$ film supported by an $\mathrm{Ag}(100)$ substrate at low temperature and then annealed to $210 \mathrm{~K}$ and to room temperature. An equivalent set is reproduced below for an eight layer thick $\mathrm{MgO}(100)$ film on $\mathrm{Ag}(100)$. The comparison of the line profiles on the right reveal the interesting result: The $\mathrm{Au}$ islands on the 3-layer film are all two-dimensional monolayer islands, the Au islands on 
the 8-layer film are three-dimensional, half-spherical in shape! This appears to corroborate the theoretical prediction $[54,55]$. However, it also implies that an 8-layer $\mathrm{MgO}(100)$ film, indeed, represents the situation encountered on a bulk oxide surface. This appears a bit surprising and needs further attention. As shown in Figure 5 both systems can be imaged using STM, i.e. tunneling through films of both thicknesses is possible. Why, then, does the 8-layer film represent the bulk so that there is no stable electron transfer leading to twodimensional growth not possible? The answer may be provided, if we analyse the different contributions that contribute to the process of electron transfer, which are schematically summarized in Figure $6[54,60]$. The cartoon on the left hand side shows a single Au atom located on top of a double layer $\mathrm{MgO}(100)$ on either $\mathrm{Ag}$ or Mo. The energetic ingredients in an electron transfer from the oxide support-metal interface are the ionization potential for an electron from this interface, the electron affinity of the adsorbed Au atom, and then any further energetic contribution that could lead to a stabilization of a transferred electron on the $\mathrm{Au}$ atom. One such contribution is the polarization of the substrate, which establishes an image charge. Another one is a possible polaronic distortion of the oxide film that would additionally stabilize the negative charge on the surface. It is this contribution that is decisive between the 3-layer and the 8-layer film. A polaronic distortion involves the phonons of the oxide [60]. Oxides in general, and $\mathrm{MgO}$, in particular, exhibit a spectrum of rather high energetic phonons. A film of 8 layers of $\mathrm{MgO}$ exhibits a phonon spectrum similar to the bulk, while the phonons of a 3-layer film are considerably softer, i.e. they may be excited with much lower energy as shown by Mario Rocca's group [61]. Therefore, the 3-layer film is able to respond to the charge and distort while the 8-layer film is not [62]. It is this subtle difference that stabilizes the negative charge on the thin film. It is possible to provide experimental evidence for this polaronic distortion for a slightly different adsorbate system via electron spin resonance spectroscopy [60]. In this case $\mathrm{O}_{2}$ forms an $\mathrm{O}_{2}^{-}$on a thin $\mathrm{MgO}(100)$ film, which is in effect the proposed precursor for thin oxide film growth as discussed by Cabrera and Mott [63]. From the measured g-tensor components the polaronic distortion can be seen in the $\mathrm{g}_{z z}$-tensor-component anomaly [60]. Coming back to Au, one may convince oneself that it is really the high electron affinity of Au that enables electron transfer by comparing individual $\mathrm{Au}$ atoms on a 3-layer $\mathrm{MgO}(100)$ film with $\mathrm{Pd}$ atoms on the same substrate. This is shown in Figure 7. In the left panel the Au atoms reveal an unusual next neighbor distribution which is not diffusion limited, while the Pd atoms in the right hand panel 
show a typical diffusion limited distribution [58]. The reason for this difference is obvious: $\mathrm{Au}$ is electronegative (2.54 on the Pauling scale) and thus negatively charged which leads to a spatial distribution where neighboring $\mathrm{Au}$ atoms avoid contact, while $\mathrm{Pd}$ atoms are much less electronegative ( 2.2 on the Pauling scale) and remain neutral, and thus show the classical pattern of a diffusing adsorbate. The collected information supports the idea of electron transfer through thin films that can lead to wetting of oxides by a metal as suggested by Pacchioni and Landmann [55]. However, how does this relate to the situation on a bulk reducible oxide, addressed in the beginning of this section, where raft-like structures have been suggested to be the active state of Au particles in CO oxidation? In other words, where is the source of electrons in the bulk material that induces the wetting phenomenon? The answer is: dopants! Imagine an oxide lattice with rock salt structure. A metal ion of this host lattice is replaced by another metal ion, which may also adopt oxidation states different from the one sufficient to replace the host ion. If the system provides electron traps with proper energy balance then an electron transfer may occur involving the oxidation of the dopant. If the electron trap is located on the surface, i.e. Au atoms and the energy balance is favorable, an electron may be transferred to the Au inducing wetting of the oxide surface by the metal. Figure 8 shows STM images of Au nano particles which have been grown on a $\mathrm{CaO}(100)$ surface. In the left image the substrate represents a thick (60 layers) pristine $\mathrm{CaO}(100)$ substrate, in the image on the right, the same substrate has been doped with a very small percentage of Mo ions [64-66]. Mo may adopt the oxidation state 2+ of the Ca ions, but may also be oxidized to Mo3+ or higher oxidation states. The insets in the large-scale images reveal the morphology of the individual nano particles. While the particles on the pristine substrate are three-dimensional, the particles on the doped substrate are two-dimensional raftlike, as indicated by the Moiré pattern on the particles. It is, therefore, clear that dopants in support materials may represent electron sources to induce two-dimensional growths of metal particles on bulk oxide surfaces, and explain the surprising experimental finding for the high activity of the raft-like structures reported by a number of laboratories. A particularly interesting observation is the fact that the influence of the dopants is not local, i.e. dopants in the deeper subsurface region influence adsorption [64].

This finding also has a number of implications for controlling the transfer of charge. These implications may be deduced from the rules that have been developed in the mature field of semiconductor physics, where dopants are regularly used to control electronic properties 
[67]. For example, if the lattice contains other electron traps such as color centers, those will compete for the charge. If, for example, $\mathrm{Li}$, as an under-valent dopant (opposed to Mo which would be called over-valent) is introduced into the $\mathrm{CaO}$ lattice, the electron transfer to the surface is suppressed and the Au nano particles grow again in three-dimensional morphology [66]. After those experimental results had been published, Hannu Häkkinen's group has published a density functional based analysis of the various energy contributions that may lead to charge transfer [68]. Their concept is similar to the acid-base concept put forward by Horia Metiu [69]. They basically show via an appropriately constructed Born-Haber cycle, that the local redox properties of the Au/surface and the Dopant/oxide pairs are responsible for the electron transfer. With this in mind, one may predict dopants that are effective in electron transfer to the surface, given that no other electron traps interfere. Another consequence of the laid out scenario is that the presence of gas phase species could influence particle growth, in particular, if the gas phase species had a large electron affinity, as, for example, oxygen molecules [23]. In fact, if one attempts to grow Au nano particles on doped $\mathrm{CaO}(100)$ surfaces in the presence of molecular oxygen, a competition between $\mathrm{Au}$ and $\mathrm{O}_{2}$ for the dopant charge is observed, which leads to a switch over in growth morphology from two-dimensional to three-dimensional depending on oxygen coverage (and pressure). This is shown in Figure 9 where STM topographic images of $0.5 \mathrm{ML}$ gold deposited onto (a) $50 \mathrm{ML}$ thick $\mathrm{CaO}$ without dopants, (b) self-doped $\mathrm{CaO}$ films of $25 \mathrm{ML}$ thickness in UHV and (c-f) in

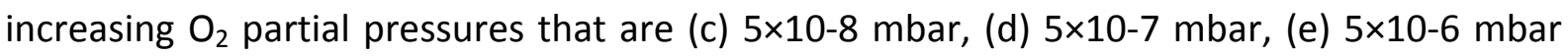
and (f) $2 \times 10-5$ mbar are depicted [23]. Note, that the two-dimensional Au deposits appear as depressions on the thick $\mathrm{CaO}$ films at the used positive bias. To support the above statement, in Figure 10 histograms [23] of Au-particle shapes for growth conditions identical to the ones shown in Figure 9 are collected: (a) non-doped $\mathrm{CaO}$ in UHV, Mo-doped $\mathrm{CaO}$ (b) in

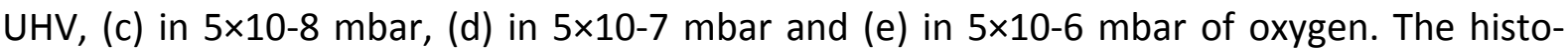
grams in (c) and (d) display bimodal shape distributions due to the coexistence of twodimensional and three-dimensional deposits. Figure $10 \mathrm{f}$ indicates the evolution of the number density of two-dimensional and three-dimensional deposits as a function of the $\mathrm{O}_{2}$ background pressure during deposition. Even though this does not provide concrete proof, these results imply, that if we would anneal two-dimensional Au nano particles in the presence of an appropriate oxygen pressure, they would switch to three-dimensional growth [70]. The latter experiments imply that $\mathrm{O}_{2}$ and $\mathrm{Au}$ compete for the electronic charge, which, in turn 
indicates that $\mathrm{O}_{2}$ may be transformed to $\mathrm{O}_{2}^{-}$which, if this could be proven, might be an active component in interesting oxidative hydrocarbon reaction.

\subsection{Strong Metal Support Interaction}

Strong metal-support interactions (SMSI) observed with particular catalyst systems, in which metal particles (such as Pd and Pt) strongly interact with a reducible support (such as titania), and are covered by a thin oxide film upon heating to elevated temperature, usually lead to reduced catalytic activity. As a consequence of SMSI the oxide film exhibits a strong attenuation of adsorption capacity and a deactivation of the system [71-73]. There have been many attempts to elucidate, even on model systems, the nature of the migrating oxide film $[74,75]$. The best studied system is $\mathrm{Pt} / \mathrm{TiO}_{2}(110)$, but in this case the attempts have been rather unsuccessful. Very recently, we succeeded in preparing such a SMSI model system for which we are able to identify the atomic structure of the encapsulating oxide film [76-78]. The system consists of Pt supported on $\mathrm{Fe}_{3} \mathrm{O}_{4}(111)$ film grown on a $\mathrm{Pt}(111)$ single crystal. Figure 11 shows an STM image of this system after heating to $850 \mathrm{~K}$. After this treatment the $\mathrm{CO}$ adsorption capacity is drastically reduced, which is typical for a SMSI effect. A close look at the STM images reveals well structured and facetted nanoparticles. Moreover, atomically resolved images reveal corrugation that does not stem from $\mathrm{Pt}$, but rather from a well ordered bi-layer $\mathrm{FeO}(111)$ film, well described and characterized in the literature [79-82]. As the oxide film that covers Pt particles has been identified, one may reduce the complexity of the model system by studying the properties of the bilayer $\mathrm{FeO}(111)$ film on a $\mathrm{Pt}(111)$ single crystal. Its structure has been studied in detail and characterized at the atomic level. The $10 \%$ misfit between the $\mathrm{FeO}(111)$ lattice constant and that of $\mathrm{Pt}(111)$ gives rise to a typical Moiré-pattern in the STM image. This film is unreactive under ultrahigh vacuum conditions [83]. The situation changes, however, dramatically if one tests the system with respect to CO oxidation at ambient conditions (1 atm) in a reactor with careful control of the relative amounts of oxygen (one part, 20 mbar), carbon monoxide (two parts, 40 mbar), and helium as buffer gas $[83,84] . \mathrm{CO}_{2}$ production was measured by gas chromatography. Only initial reaction rates (towards zero conversion) were used to compare data on different systems. If one ramps the temperature linear with $1 \mathrm{Kmin}^{-1}$ from 300 to $455 \mathrm{~K}$, CO oxidation ignites at $430 \mathrm{~K}$. The interesting observation is that this $\mathrm{FeO} / \mathrm{Pt}(111)$ system at this temperature is more than an order of magnitude more reactive than clean Pt(111). Usually, SMSI leads to 
an attenuated activity, while here we observe a strong enhancement! Further studies as a function of different gas compositions, as well as thermal desorption studies, STM investigations, and detailed DFT model calculations reveal an interesting scenario that allows us to understand this phenomenon [78]. The scenario is depicted in Figure 12 [78, 85, 86]. The gas phase sets the chemical potential of the system. The shown steps are based on density functional calculations. Oxygen interacts with the bi-layer FeO film on $\mathrm{Pt}(111)$ by pulling an iron atom up above the oxygen layer. This lowers the work function at the interface locally to allow for an electron transfer towards oxygen accompanied by the formation of a transient $a_{2}^{-}$molecule, which dissociates and results, at higher oxygen coverage, in the formation of a local O-Fe-O trilayer. There is a range of experimental evidence for the existence of such a trilayer $[78,85,86]$. The middle panel in Figure 12 shows an STM image of such a trilayer formed in-situ at elevated $\mathrm{O}_{2}$ pressure in a microscope. The trilayers appearance is mostly determined by the Moiré structure of the FeO bi-layer and fills $80-90 \%$ of the surface as thermal desorption spectra indicate. The STM images are completely consistent with the structure suggested by the calculation, although the latter does not reproduce the patched morphology due to the enormous size of the unit cell, which was impossible to implement, but necessary to fully reproduce the details. Nevertheless, if the trilayer is exposed to carbon monoxide it oxidizes the incoming $\mathrm{CO}$ to $\mathrm{CO}_{2}$ by means of an Eley-Rideal mechanism, leaving behind an oxygen vacancy in the film. At sufficiently high oxygen pressure the oxygen vacancy is filled again and the trilayer is sustained. If, however, the gas phase is oxygen-poor, the reaction finally stops because the trilayer is destroyed. Experimentally, we have confirmed [84] that the iron oxide film de-wets the $\mathrm{Pt}(111)$ surface under CO-rich reaction conditions by forming small iron oxide particles, exposing the Pt(111) surface underneath, which then determines the reactivity of the systems, in contrast to a recent study in the literature [87]. Heating the de-wetted surface in vacuum again leads to the formation of the FeO double layer, which then, at higher oxygen pressure, may be transformed into the trilayer again. As suggested in this section thin oxide films exhibit very interesting catalytic activity which will depend on the materials combination between the metal and the covering oxide film. It may be possible to design, by choosing appropriate combinations of materials, systems with specific catalytic reactivities. Temperature programmed desorption results indeed reveal that a tri-layer film contains much more weakly bound oxygen than in a pristine bilayer FeO film [78]. Therefore, it appears that the binding energy of the oxygen in the top-most layer gov- 
erns the activity of the system. To verify this hypothesis, we have investigated other transition metal oxide films on the same Pt(111) support. For comparison, we also studied reactivity of oxide films prepared on Ru(0001) [88].

Figure 13 collects 32 amu $\left(\mathrm{O}_{2}\right)$ traces in TPD spectra resulting from re-combinative atomic oxygen desorption of a series of ultrathin film systems, all exposed to $20 \mathrm{mbar}$ of $\mathrm{O}_{2}$ at $450 \mathrm{~K}$ for $10 \mathrm{~min}$. Except $\mathrm{ZnO}$, these films showed desorption signals at temperatures, which are much below the "decomposition" temperature $(1000-1200 \mathrm{~K})$ and follow a series $\mathrm{Ru}<<\mathrm{Fe}$ $<\mathrm{Mn}$. In turn, the CO oxidation rate measured under identical conditions (10 mbar CO; 50 mbar $\mathrm{O}_{2}$; He balance to 1 bar at $450 \mathrm{~K}$ ) over these closed films follows the opposite row, i.e. $\mathrm{Ru}>>\mathrm{Fe}>\mathrm{Mn}>\mathrm{Zn}$ [89]. Clearly, there is a correlation between the activity and the presence of weakly bound oxygen species on the film surfaces at high chemical potential of oxygen which is basically set by oxygen partial pressure.

\subsection{Two-dimensional silica and alumino-silicates towards a surface science of zeolites}

Silica belongs to the most important supports in catalysis [1]. For more than a decade has the group been involved in the preparation of well-ordered silica films [25, 90-98]. The first successful attempt led to a monolayer $\mathrm{SiO}_{2.5}$ film on $\mathrm{Mo}(112)$ that has been used frequently by a number of groups as a model support $[90,99]$. This film consists of a hexagonal network of corner shared $\mathrm{SiO}_{4}$ tetrahedra, with the one $\mathrm{Si}-\mathrm{O}$ bond, not associated with the intra silica network establishing a strong bond to the Mo(112) substrate. Since the stoichiometry of this film did not properly represent silica with a 1:2 Si:O ratio, the search continued and led to the preparation of a double layer $\mathrm{SiO}_{2}$ silica film, which consists of two single layer corner shared $\mathrm{SiO}_{4}$ networks as in the case of the film on $\mathrm{Mo}(112)$ where, however, the Si-O bond formed to bind to Mo is now used to bind to the other identical monolayer silica network. This double layer film is only weakly bound to a Ru(0001) substrate [91]. It comes as a crystalline film, and, depending on preparation conditions also as a vitreous film [25, 95-97]. An equivalent to the originally prepared monolayer film on $\mathrm{Mo(112)}$ may also be prepared on $\mathrm{Ru}(0001)$ and the properties may directly be compared with the double layer film [25]. Figure 14 shows the structures of the two thin film systems, addressed above together with their vibrational spectra. The spectra are shown in order to provide evidence that the two systems, although similar in symmetry, may be clearly differentiated via their vibrational properties [100]. The experimental observations are very well supported by density func- 
tional calculations from the group of Joachim Sauer $[90,91,100]$. In fact, the structural parameters are, to a large extent, based on the theoretical studies [90, 91, 100]. While we are not going through a detailed analysis of the spectra, which has been presented elsewhere $[90,91,100]$, it may suffice to mention that the strongest phonons at $\sim 1100$ and $1300 \mathrm{~cm}^{-1}$ refers to the Si-O-Si and Si-O-metal bonds, respectively. Figure 15 collects STM images of the crystalline (a) and vitreous (f) structures together with schematic representations of the structures [25]. While the crystalline film consists of six membered rings only (b and c), the vitreous film exhibits a variation of ring sizes varying between 4 and 9 membered rings ( $g$ and h) still with a maximum at the six membered ring size, as predicted by Zachariasen in 1932 [95-97, 101]. The sizes follow a log-normal distribution. Both films are being explored for their use as model supports for metals. In fact, metal atoms have already been adsorbed onto and into them, and their electronic structure is explored at present ( $d, e, g, j)$.

A direct comparison between Au (Fig. 15 d, i) and Pd (Fig. 15 e, j) adsorbed on freshly prepared silica films with cut-outs of crystalline (Fig. 15 d, e) and vitreous (Fig. 15. i, j) patches is provided. Au adsorbs only on vitreous while Pd can adsorb on both phases. Au seems to favor larger pores as adsorption sites [102].

Another interesting research area for our group with respect to silica films is to replace silicon atoms by other metal atoms. One particular direction is the exploration of alumino silicates as models for two-dimensional zeolites [103-105]. As it turns out, both, the monolayer as well as the double layer silica films allow for the preparation of alumino silicates following the Löwenstein rule for nearest Al-Al distances. The expectation is that due to the substitution of the quatrivalent $\mathrm{Si}$ by the trivalent $\mathrm{Al}$ the oxygen atoms in bridging positions try to compensate the valence imbalance by picking up hydrogen [106]. However, due to the presence of the metal substrate, the valence imbalance is screened by the metal for the monolayer film, so that hydrogen take up cannot be detected [103]. On the other hand, the double layer film in the top layer does, indeed, takes up hydrogen as may be unambiguously proven by isotopic hydrogen/deuterium exchange $[104,105]$. This renders the alumino silicate double layer film to be a flat or two-dimensional model for zeolites, given that it would be possible to prove the high acidity of the adsorbed hydrogen [104, 105]. Figure 16 collects infrared spectra taken on the alumino silicate film. The topmost trace refers to the hydrogen/deuterium exchange. "Positive" peaks are indicative of species that have been replaced 
on the surface. "Negative" peaks are indicative of newly adsorbed species, and clearly reveal the result of the H-D exchange process. In order to evaluate the acidity of the hydroxyl groups we resort to the adsorption of probe molecules, a procedure well known in zeolite characterization. The second and third traces from the top are infrared spectra recorded after exposure of the hydrogenated alumino silicate surface to $\mathrm{CO}$. The $\mathrm{CO}$ interacts preferentially with the hydroxyl groups and their frequency is shifted in a characteristic way. In addition, the stretching frequency of the adsorbed CO molecules is visible at $2183 \mathrm{~cm}^{-1}$, which is shifted to higher frequencies from the gas phase value. The absolute value of the shift is a measure for the acidity of the hydroxyls at the surface. The observed shifts of 249 and $391 \mathrm{~cm}^{-1}$ for $v(\mathrm{OD})$ and $v(\mathrm{OH})$, respectively, are relatively large and are indicative of an acidity of the hydroxyls on the two-dimensional alumino silicate similar to chabasite. Another weak base, i.e. ethene, has been tried [107]. The results are similar. Two strong bases have also been tested, i.e. ammonia and pyridine, which lead to the formation of ammonium and pyridinium species [107]. The spectrum after adsorption of ammonia is shown as the forth trace in Figure 16. The hydroxyl groups are being consumed, and the two new bands occurring at 3398 and $1502 \mathrm{~cm}^{-1}$ are consistent, according to density functional calculations from Joachim Sauer's group [107], with the formation of ammonium species adsorbed atop the hexagonal rings.

Figure 17 shows an STM image containing a variety of distinct features [104]. Similar to the case of an ordered pure-silica bilayer system the majority of the framework is composed of double 6-membered rings ( $d 6 r)$. In the case of the ordered silica film, as well as the vitreous one, bright protrusions arranged as triangles were assigned to the position of the top-most oxygen atoms in the film, where these three $\mathrm{O}$ atoms are bound to the same tetrahedral atom [95-97]. Although only the immediate surface can be seen in the image, evidence of the same structure, symmetrically repeating below, is given by IRAS, as in the case of the pure silica films [105]. Figure 17 shows the presence of structures lacking long-range order. Close-ups of $1.5 \times 1.5 \mathrm{~nm}$ sections of the large scale image showing double $\mathrm{N}$-membered rings are shown in insets $a(d 6 r), b(d 4 r$ and $d 8 r)$ and $c(d 5 r$ and $d 7 r)$. In these insets, the position of the tetrahedral $\mathrm{T}$ atoms is shown in green while the $\mathrm{O}$ atoms are shown in red. Insets $a^{\prime}, b^{\prime}$ and $c^{\prime}$ show connected-dots representations where the different ring sizes are emphasized by different colors. Summarizing a large body of statistical information we come to conclude that polygonal prisms of tetrahedral atoms, which constitute the building blocks 
of significant number of zeolites are identified with atomic resolution in a flat aluminosilicate. A substantial increase is observed in the population of prisms with even-numbered rings, when compared to analogous pure-silica systems. These units had been previously proposed as precursors for the zeolite formation. In particular, the number of double fourmembered rings (cubes) shows a significant increase. In addition, we note a close topological relation between this planar aluminosilicate and zeolite $A[108]$.

It is our feeling that the study of two-dimensional zeolite film opens up an avenue for surface science to provide some evidence for details of chemical reactions on zeolites using a combination of scanning probe and spectroscopic techniques that are difficult to obtain otherwise.

\section{Conclusion and outlook}

The four case studies presented were supposed to demonstrate and underline how model studies may be employed to investigate complex problems in catalysis leading to unexpected points of view that may influence our thinking for future research. The first case study could stimulate our thinking with respect to enantiospecific hydrogenation reactions at nano particles. The second one could initiate further studies towards a more systematic analysis of the influence of dopants and the effect of electron traps in more complex powder materials. Case study number three may motivate an investigation of materials combinations that could profitably be used as SMSI systems. In the last example we presented a case study that might open up possibilities to study reactions on zeolite like surfaces using local probe techniques.

We have only chosen a small number of case studies, however, model catalysis holds the potential to contribute in many areas of catalysis, in particular when techniques are employed to work under ambient conditions. Our group has started recently to look into those processes that are involved in the preparation of metal nano particles from a wet chemical environment using a combination of spectroscopic (non linear optical) techniques and (electrochemical) scanning probe techniques. We believe there is much more to come to close the gap between models and real catalysts. 


\section{Acknowledgment}

We would like to thank our present and previous collaborators, mentioned in the references for their key contributions. We are also grateful for enlightening discussions with Gianfranco Pacchioni, Notker Rösch, and Joachim Sauer. Support was received from the cluster of excellence UniCat coordinated by the Technische Universitität Berlin and by the Fonds der Chemischen Industrie.

\section{References:}

[1] in: G. Ertl, H. Knözinger, F. Schüth, J. Weitkamp (Eds.) Handbook of Heterogeneous Catalysis, Wiley-VCH, Weinheim, 2008.

[2] G. Somorjai, Chemistry in two dimensions: surfaces, Cornell University Press, Ithaca, 1981.

[3] D.J. Auerbach, B.E. Bent, L.H. Dubois, in: R.J. Madix (Ed.) Surface Reactions, SpringerVerlag, Berlin, Heidelberg, New York, London, Paris, 1994, pp. 277.

[4] K.H. Hansen, T. Worren, S. Stempel, E. Lægsgaard, M. Bäumer, H.J. Freund, F. Besenbacher, I. Stensgaard, Palladium Nanocrystals on $\mathrm{Al}_{2} \mathrm{O}_{3}$ : Structure and Adhesion Energy, Phys. Rev. Lett., 83 (1999) 4120-4123.

[5] G. Ertl, Reactions at Solid Surfaces, John Wiley \& Sons, Hoboken, 2009.

[6] G. Ertl, Reactions at Surfaces: From Atoms to Complexity (Nobel Lecture), Angew. Chem. Int. Ed., 47 (2008) 3524-3535.

[7] G. Ertl, H.-J. Freund, Catalysis and surface science, Phys. Today, 52 (1999) 32-38.

[8] S. Ulrich, N. Nilius, H.-J. Freund, Growth of thin alumina films on a vicinal NiAl surface, Surf. Sci., 601 (2007) 4603-4607.

[9] H.J. Freund, Model Studies in Heterogeneous Catalysis, Chem. Eur. J., 16 (2010) 93849397.

[10] S. Schauermann, N. Nilius, S. Shaikhutdinov, H.-J. Freund, Nanoparticles for Heterogeneous Catalysis: New Mechanistic Insights, Acc. Chem. Res., (2012).

[11] H.-J. Freund, G. Pacchioni, Oxide ultra-thin films on metals: new materials for the design of supported metal catalysts, Chem. Soc. Rev., 37 (2008) 2224-2242.

[12] G. Pacchioni, H. Freund, Electron Transfer at Oxide Surfaces. The MgO Paradigm: from Defects to Ultrathin Films, Chem. Rev., (2012).

[13] H. Kuhlenbeck, S. Shaikhutdinov, H.-J. Freund, Well-ordered Transition Metal Oxide Layers in Model Catalysis - A Series of Case Studies, Chem. Rev., accepted (2013).

[14] H.-J. Freund, N. Nilius, T. Risse, S. Schauermann, T. Schmidt, Innovative Measurement Techniques in Surface Science, ChemPhysChem, 12 (2011) 79-87.

[15] C.B. Duke, Surface Science: The First Thirty Years, Surf. Sci., 299/300 (1994) vii-viii.

[16] C.B. Duke, E.W. Plummer, Special Issue of Surface Science, Vol. 500: "Frontiers in Surface and Interface Science", North-Holland, Amsterdam, 2002.

[17] W. Ludwig, A. Savara, S. Schauermann, H.-J. Freund, Role of Low-Coordinated Surface Sites in Olefin Hydrogenation: A Molecular Beam Study on Pd Nanoparticles and Pd(111), ChemPhysChem, 11 (2010) 2319-2322. 
[18] W. Ludwig, A. Savara, R.J. Madix, S. Schauermann, H.-J. Freund, Subsurface Hydrogen Diffusion into Pd Nanoparticles: Role of Low-Coordinated Surface Sites and Facilitation by Carbon, J. Phys. Chem. C, 116 (2012) 3539-3544.

[19] J.M. Flores-Camacho, J.H. Fischer-Wolfarth, M. Peter, C.T. Campbell, S. Schauermann, H.J. Freund, Adsorption energetics of $\mathrm{CO}$ on supported $\mathrm{Pd}$ nanoparticles as a function of particle size by single crystal microcalorimetry, Phys. Chem. Chem. Phys., 13 (2011) 16800-16810.

[20] M. Peter, J.M. Flores-Camacho, S. Adamovski, L.K. Ono, K.-H. Dostert, C.P. O'Brien, B. Roldan, S. Schauermann, H.-J. Freund, Trends in Binding Strength of Surface Species on Nanoparticles: How does the Adsorption Energy Scale with the Particle Size?, Angew. Chem. Int. Ed., 52 (2013) 5175-5179.

[21] H.-J. Freund, Metal-supported ultrathin oxide film systems as designable catalysts and catalyst supports, Surf. Sci., 601 (2007) 1438-1442.

[22] T. Risse, S. Shaikhutdinov, N. Nilius, M. Sterrer, H.-J. Freund, Gold Supported on Thin Oxide Films: From Single Atoms to Nanoparticles, Acc. Chem. Res., 41 (2008) 949-956.

[23] Y. Cui, K. Huang, N. Nilius, H.-J. Freund, Faraday Discussions 162: Fabrication, Structure and Reactivity of Anchored Nanoparticles: Charge competition with oxygen molecules determines the growth of gold particles on doped CaO films, Faraday Discuss., 162 (2013) 1-11.

[24] S. Shaikhutdinov, H.-J. Freund, Ultrathin Oxide Films on Metal Supports: StructureReactivity Relations, Ann. Rev. Phys. Chem., 63 (2012) 619-633.

[25] M. Heyde, S. Shaikhutdinov, H.-J. Freund, Two-dimensional silica: Crystalline and vitreous, Chem. Phys. Lett., 550 (2012) 1-7.

[26] S. Shaikhutdinov, H.-J. Freund, Metal-Supported Aluminosilicate Ultrathin Films as a Versatile Tool for Studying the Surface Chemistry of Zeolites, ChemPhysChem, 14 (2013) 71-77.

[27] M. Wilde, K. Fukutani, W. Ludwig, B. Brandt, J.-H. Fischer, S. Schauermann, H.J. Freund, Influence of Carbon Deposition on the Hydrogen Distribution in Pd Nanoparticles and Their Reactivity in Olefin Hydrogenation, Angew. Chem. Int. Ed., 47 (2008) 9289-9293.

[28] B. Brandt, J.H. Fischer, W. Ludwig, J. Libuda, F. Zaera, S. Schauermann, H.J. Freund, Isomerization and hydrogenation of cis-2-butene on Pd model catalyst, J. Phys. Chem. C, 112 (2008) 11408-11420.

[29] J. Horiuti, M. Polanyi, Trans. Faraday. Soc., 30 (1934) 1164.

[30] A.M. Doyle, S.K. Shaikhutdinov, S.D. Jackson, H.-J. Freund, Hydrogenation on Metal Surfaces: Why are Nanoparticles More Active than Single Crystals?, Angew. Chem. Int. Ed., 42 (2003) 5240-5243.

[31] K.M. Neyman, S. Schauermann, Hydrogen Diffusion into Palladium Nanoparticles: Pivotal Promotion by Carbon13, Angew. Chem. Int. Ed., 49 (2010) 4743-4746.

[32] G. Webb, Comprehensive Chemical Kinetics, 20 (1978) 1.

[33] G. Webb, The formation and role of carbonaceous residues in metal-catalysed reactions of hydrocarbons, Catal. Today, 7 (1990) 139-155.

[34] G.C. Bond, Metal-Catalysed Reactions of Hydrocarbons, Springer, New York, 2005.

[35] L.L. Kesmodel, J.A. Gates, Ethylene adsorption and reaction on Pd(111): An angledependent EELS analysis, Surf. Sci., 111 (1981) L747-L754.

[36] T.P. Beebe, J.T. Yates, An in situ infrared spectroscopic investigation of the role of ethylidyne in the ethylene hydrogenation reaction on palladium/alumina, J. Am. Chem. Soc., 108 (1986) 663-671. 
[37] C.E. Borronibird, D.A. King, An Ultrahigh-Vacuum Single-Crystal Adsorption Microcalorimeter, Rev. Sci. Instrum., 62 (1991) 2177-2185.

[38] J.H. Fischer-Wolfarth, J. Hartmann, J.A. Farmer, J.M. Flores-Camacho, C.T. Campbell, S. Schauermann, H.-J. Freund, An improved single crystal adsorption calorimeter for determining gas adsorption and reaction energies on complex model catalysts, Rev. Sci. Instrum., 82 (2011) 024102.

[39] J.-H. Fischer-Wolfarth, J.A. Farmer, J.M. Flores-Camacho, A. Genest, I.V. Yudanov, N. Rösch, C.T. Campbell, S. Schauermann, H.-J. Freund, Particle-size dependent heats of adsorption of $\mathrm{CO}$ on supported $\mathrm{Pd}$ nanoparticles as measured with a single-crystal microcalorimeter, Phys. Rev. B, 81 (2010) 241416.

[40] S. Krüger, S. Vent, F. Nörtemann, M. Staufer, N. Rösch, The average bond length in Pd clusters $\mathrm{Pd}_{n}, \mathrm{n}=4$-309: A density-functional case study on the scaling of cluster properties, J. Chem. Phys., 115 (2001) 2082-2087.

[41] P. Nava, M. Sierka, R. Ahlrichs, Density functional study of palladium clusters, Phys. Chem. Chem. Phys., 5 (2003) 3372-3381.

[42] O.D. Häberlen, S.-C. Chung, M. Stener, N. Rösch, J. Chem. Phys., 106 (1997) 5189-5201.

[43] I.V. Yudanov, R. Sahnoun, K.M. Neyman, N. Rösch, Metal nanoparticles as models of single crystal surfaces and supported catalysts: Density functional study of size effects for CO/Pd(111), J. Phys. Chem., 117 (2002) 9887-9896.

[44] I.V. Yudanov, M. Metzner, A. Genest, N. Rösch, Size-Dependence of Adsorption Properties of Metal Nanoparticles: A Density Functional Study on Palladium Nanoclusters, J. Phys. Chem. C, 112 (2008) 20269-20275.

[45] E. Shustorovich, H. Sellers, The UBI-QEP method: A practical theoretical approach to understanding chemistry on transition metal surfaces, Surf. Sci. Rep., 31 (1998) 1-119.

[46] R.A. van Santen, G.J. Kramer, Reactivity Theory of Zeolitic Broensted Acidic Sites, Chem. Rev., 95 (1995) 637-660.

[47] K. Watanabe, Y. Matsumoto, M. Kampling, K. Al-Shamery, H.-J. Freund, Photochemistry of Methane on $\mathrm{Pd} / \mathrm{Al}_{2} \mathrm{O}_{3}$ Model Catalysts: Control of Photochemistry on Transition Metal Surfaces, Angew. Chem. Int. Ed., 38 (1999) 2192-2194.

[48] D. Mulugeta, K.H. Kim, K. Watanabe, D. Menzel, H.-J. Freund, Size Effects in Thermal and Photochemistry of (NO) ${ }_{2}$ on Ag Nanoparticles, Phys. Rev. Lett., 101 (2008) 146103.

[49] S.A. Nepijko, M. Klimenkov, M. Adelt, H. Kuhlenbeck, R. Schlögl, H.-J. Freund, Structural investigation of palladium clusters on $\gamma-\mathrm{Al}_{2} \mathrm{O}_{3}(111) / \mathrm{NiAl}(110)$ with transmission electron microscopy, Langmuir, 15 (1999) 5309-5313.

[50] M. Haruta, S. Tsubota, T. Kobayashi, H. Kageyama, M.J. Genet, B. Delmon, LowTemperature Oxidation of $\mathrm{CO}$ over Gold Supported on $\mathrm{TiO}_{2}, \alpha-\mathrm{Fe}_{2} \mathrm{O}_{3}$, and $\mathrm{Co}_{3} \mathrm{O}_{4}, \mathrm{~J}$. Catal., 144 (1993) 175-192.

[51] M. Chen, D.W. Goodman, Catalytically active gold on ordered titania supports, Chem. Soc. Rev., 37 (2008) 1860-1870.

[52] S.N. Rashkeev, A.R. Lupini, S.H. Overbury, S.J. Pennycook, S.T. Pantelides, Role of the nanoscale in catalytic $\mathrm{CO}$ oxidation by supported Au and Pt nanostructures, Phys. Rev. B, 76 (2007) 035438.

[53] A.A. Herzing, C.J. Kiely, A.F. Carley, P. Landon, G.J. Hutchings, Identification of Active Gold Nanoclusters on Iron Oxide Supports for CO Oxidation, Science, 321 (2008) 13311335.

[54] G. Pacchioni, L. Giordano, M. Baistrocchi, Charging of Metal Atoms on Ultrathin MgO/Mo(100) Films, Phys. Rev. Lett., 94 (2005) 226104. 
[55] D. Ricci, A. Bongiorno, G. Pacchioni, U. Landman, Bonding Trends and Dimensionality Crossover of Gold Nanoclusters on Metal-Supported MgO Thin Films, Phys. Rev. Lett., 97 (2006) 036106.

[56] J. Li, X. Li, H.-J. Zhai, L.-S. Wang, Au 20 : A Tetrahedral Cluster, Science, 299 (2003) 864867.

[57] M. Sterrer, T. Risse, M. Heyde, H.-P. Rust, H.-J. Freund, Crossover from ThreeDimensional to Two-Dimensional Geometries of Au Nanostructures on Thin MgO(001) Films: A Confirmation of Theoretical Predictions, Phys. Rev. Lett., 98 (2007) 206103.

[58] M. Sterrer, T. Risse, U. Martinez Pozzoni, L. Giordano, M. Heyde, H.-P. Rust, G. Pacchioni, H.-J. Freund, Control of the Charge State of Metal Atoms on Thin MgO Films, Phys. Rev. Lett., 98 (2007) 096107.

[59] M. Yulikov, M. Sterrer, T. Risse, H.J. Freund, Gold atoms and clusters on $\mathrm{MgO}(100)$ films; an EPR and IRAS study, Surf. Sci., 603 (2009) 1622-1628.

[60] A. Gonchar, T. Risse, H.-J. Freund, L. Giordano, C. Di Valentin, G. Pacchioni, Activation of Oxygen on MgO: $\mathrm{O}_{2}{ }^{-}$Radical Ion Formation on Thin, Metal-Supported MgO(001) Films, Angew. Chem. Int. Ed., 50 (2011) 2635-2638.

[61] L. Savio, E. Celasco, L. Vattuone, M. Rocca, P. Senet, MgO/Ag(100): Confined vibrational modes in the limit of ultrathin films, Phys. Rev. B, 67 (2003) 075420.

[62] C.J. Nelin, P.S. Bagus, M.A. Brown, M. Sterrer, H.-J. Freund, Analysis of the Broadening of X-ray Photoelectron Spectroscopy Peaks for Ionic Crystals, Angew. Chem. Int. Ed., 50 (2011) 10174-10177.

[63] N. Cabrera, N.F. Mott, Theory of the oxidation of metals, Rep. Progr. Phys., 12 (1948) 163.

[64] X. Shao, S. Prada, L. Giordano, G. Pacchioni, N. Nilius, H.-J. Freund, Tailoring the Shape of Metal Ad-Particles by Doping the Oxide Support, Angew. Chem. Int. Ed., 50 (2011) 11525-11527.

[65] X. Shao, N. Nilius, H.-J. Freund, Crossover from two- to three-dimensional gold particle shapes on CaO films of different thicknesses, Phys. Rev. B, 85 (2012) 115444.

[66] X. Shao, N. Nilius, H.-J. Freund, Li/Mo Codoping of CaO Films: A Means to Tailor the Equilibrium Shape of Au Deposits, J. Am. Chem. Soc., 134 (2012) 2532-2534.

[67] P. Yu, M. Cardona, Fundamentals of Semiconductors: Physics and Materials Properties, in, Springer, Berlin Heidelberg 2010.

[68] J. Andersin, J. Nevalaita, K. Honkala, H. Häkkinen, The Redox Chemistry of Gold with High-Valence Doped Calcium Oxide, Angew. Chem. Int. Ed., (2012) 14124-11427.

[69] H. Metiu, S. Chrétien, Z. Hu, B. Li, X. Sun, Chemistry of Lewis Acid-Base Pairs on Oxide Surfaces, J. Phys. Chem. C, 116 (2012) 10439-10450.

[70] P.L. Hansen, J.B. Wagner, S. Helveg, J.R. Rostrup-Nielsen, B.S. Clausen, H. Topsoe, Atom-Resolved Imaging of Dynamic Shape Changes in Supported Copper Nanocrystals Science, 295 (2002) 2053-2055.

[71] S.J. Tauster, Strong metal-support interactions, Acc. Chem. Res., 20 (1987) 389-394.

[72] G.L. Haller, D.E. Resasco, Metal-support interactions between Group VIII metals and reducible oxides, Adv. Catal., 36 (1989) 173.

[73] F. Solymosi, Comments on electronic effects in strong metal-support interactions on titania-deposited metal catalysts, J. Catal., 94 (1985) 581-585.

[74] O. Dulub, W. Hebenstreit, U. Diebold, Imaging Cluster Surfaces with Atomic Resolution: The Strong Metal-Support Interaction State of Pt Supported on $\mathrm{TiO}_{2}(110)$, Phys. Rev. Lett., 84 (2000) 3646-3649. 
[75] Q.-H. Wu, A. Fortunelli, G. Granozzi, Preparation, characterisation and structure of Ti and Al ultrathin oxide films on metals, Int. Rev. Phys. Chem., 28 (2009) 517-576.

[76] Z.H. Qin, M. Lewandowski, Y.N. Sun, S. Shaikhutdinov, H.J. Freund, Encapsulation of Pt Nanoparticles as a Result of Strong Metal-Support Interaction with $\mathrm{Fe}_{3} \mathrm{O}_{4}(111)$, J. Phys. Chem. C, 112 (2008) 10209-10213.

[77] Z.H. Qin, M. Lewandowski, Y.N. Sun, S. Shaikhutdinov, H.J. Freund, Morphology and CO adsorption on platinum supported on thin $\mathrm{Fe}_{3} \mathrm{O}_{4}(111)$ films, J. Phys.: Condens. Matter, 21 (2009) 134019.

[78] Y.-N. Sun, L. Giordano, J. Goniakowski, M. Lewandowski, Z.-H. Qin, C. Noguera, S. Shaikhutdinov, G. Pacchioni, H.-J. Freund, The Interplay between Structure and CO Oxidation Catalysis on Metal-Supported Ultrathin Oxide Films, Angew. Chem. Int. Ed., 49 (2010) 4418-4421.

[79] G.H. Vurens, M. Salmeron, G.A. Somorjai, Structure, composition and chemisorption studies of thin ordered iron oxide films on platinum (111), Surf. Sci., 201 (1988) 129144.

[80] W. Weiss, A. Barbieri, M.A. Van Hove, G.A. Somorjai, Surface structure determination of an oxide film grown on a foreign substrate: $\mathrm{Fe}_{3} \mathrm{O}_{4}$ multilayer on $\mathrm{Pt}(111)$ identified by low energy electron diffraction, Phys. Rev. Lett., 71 (1993) 1848.

[81] H.C. Galloway, J.J. Benítez, M. Salmeron, The structure of monolayer films of FeO on Pt(111), Surf. Sci., 298 (1993) 127-133.

[82] Y.J. Kim, C. Westphal, R.X. Ynzunza, Z. Wang, H.C. Galloway, M. Salmeron, M.A. Van Hove, C.S. Fadley, The growth of iron oxide films on Pt (111): A combined XPD, STM, and LEED study, Surf. Sci., 416 (1998) 68-111.

[83] Y.N. Sun, Z.H. Qin, M. Lewandowski, E. Carrasco, M. Sterrer, S. Shaikhutdinov, H.J. Freund, Monolayer iron oxide film on platinum promotes low temperature $\mathrm{CO}$ oxidation, J. Catal., 266 (2009) 359-368.

[84] Y.-N. Sun, Z.-H. Qin, M. Lewandowski, S. Kaya, S. Shaikhutdinov, H.-J. Freund, When an Encapsulating Oxide Layer Promotes Reaction on Noble Metals: Dewetting and In situ Formation of an "Inverted" FeO(x)/Pt Catalyst, Catal. Lett., 126 (2008) 31-35.

[85] M. Lewandowski, Y.N. Sun, Z.H. Qin, S. Shaikhutdinov, H.J. Freund, Promotional effect of metal encapsulation on reactivity of iron oxide supported Pt catalysts, Appl. Catal., A, 391 (2011) 407-410.

[86] L. Giordano, M. Lewandowski, I.M.N. Groot, Y.N. Sun, J. Goniakowski, C. Noguera, S. Shaikhutdinov, G. Pacchioni, H.J. Freund, Oxygen-Induced Transformations of an FeO(111) Film on Pt(111): A Combined DFT and STM Study, J. Phys. Chem. C, 114 (2010) 21504-21509.

[87] Q. Fu, W.-X. Li, Y. Yao, L. Hongyang, Q. Fu, H.-Y. Su, D. Ma, X.-K. Gu, L. Chen, Z. Wang, H. Zhang, B. Wang, X. Bao, Interface-Confined Ferrous Centers for Catalytic Oxidation, Science, 328 (2010) 1141 - 1144.

[88] Y. Martynova, B. Yang, X. Yu, J.A. Boscoboinik, S. Shaikhutdinov, H.J. Freund, Low Temperature CO Oxidation on Ruthenium Oxide Thin Films at Near-Atmospheric Pressures, Catal. Lett., 142 (2012) 657-663.

[89] Y. Martynova, B.-H. Liu, M.E. McBriarty, I.M.N. Groot, M.J. Bedzyk, S. Shaikhutdinov, H.-J. Freund, CO oxidation over ZnO films on Pt(111), ChemCatChem, to be published (2013).

[90] J. Weissenrieder, S. Kaya, J.-L. Lu, H.-J. Gao, S. Shaikhutdinov, H.-J. Freund, M. Sierka, T.K. Todorova, J. Sauer, Atomic Structure of a Thin Silica Film on a Mo(112) Substrate: A Two-Dimensional Network of $\mathrm{SiO}_{4}$ Tetrahedra, Phys. Rev. Lett., 95 (2005) 076103. 
[91] D. Loeffler, J.J. Uhlrich, M. Baron, B. Yang, X. Yu, L. Lichtenstein, L. Heinke, C. Büchner, M. Heyde, S. Shaikhutdinov, H.J. Freund, R. Wlstrokodarczyk, M. Sierka, J. Sauer, Growth and Structure of Crystalline Silica Sheet on Ru(0001), Phys. Rev. Lett., 105 (2010) 146104.

[92] D.J. Stacchiola, M. Baron, S. Kaya, J. Weissenrieder, S. Shaikhutdinov, H.-J. Freund, Growth of Stoichiometric Subnanometer Silica Films, Appl. Phys. Lett., 92 (2008) 0119111-0119113.

[93] T. Schröder, M. Adelt, B. Richter, M. Naschitzki, M. Bäumer, H.-J. Freund, Epitaxial Growth of $\mathrm{SiO}_{2}$ on Mo(112), Surf. Rev. Lett., 7 (2000) 7-14.

[94] X. Yu, B. Yang, J.A. Boscoboinik, S. Shaikhutdinov, H.-J. Freund, Support effects on the atomic structure of ultrathin silica films on metals, Appl. Phys. Lett., 100 (2012) 151608.

[95] L. Lichtenstein, C. Büchner, B. Yang, S. Shaikhutdinov, M. Heyde, M. Sierka, R. Włodarczyk, J. Sauer, H.-J. Freund, The Atomic Structure of a Metal-Supported Vitreous Thin Silica Film, Angew. Chem. Int. Ed., 51 (2012) 404-407.

[96] L. Lichtenstein, M. Heyde, H.-J. Freund, Crystalline-Vitreous Interface in Two Dimensional Silica, Phys. Rev. Lett., 109 (2012) 106101.

[97] L. Lichtenstein, M. Heyde, H.-J. Freund, Atomic Arrangement in Two-Dimensional Silica: From Crystalline to Vitreous Structures, J. Phys. Chem. C, 116 (2012) 20426-20432.

[98] S. Shaikhutdinov, H.-J. Freund, Ultrathin Silica Films on Metals: The Long and Winding Road to Understanding the Atomic Structure, Adv. Mater., 25 (2013) 49-67.

[99] H.-J. Freund, D.W. Goodman, Ultrathin Oxide Films, in: G. Ertl, H. Knözinger, F. Schüth, J. Weitkamp (Eds.) Handbook of Heterogeneous Catalysis, Wiley-VCH Verlagsgesellschaft mbH, Weinheim, 2008, pp. 1309-1338.

[100] B. Yang, W.E. Kaden, X. Yu, J.A. Boscoboinik, Y. Martynova, L. Lichtenstein, M. Heyde, M. Sterrer, R. Wlodarczyk, M. Sierka, J. Sauer, S. Shaikhutdinov, H.-J. Freund, Thin silica films on $\mathrm{Ru}(0001)$ : monolayer, bilayer and three-dimensional networks of [ $\left.\mathrm{SiO}_{4}\right]$ tetrahedra, Phys. Chem. Chem. Phys., 14 (2012) 11344-11351.

[101] W.H. Zachariasen, The atomic arrangement in glass, J. Am. Chem. Soc., 54 (1932) 38413851.

[102] C. Büchner, in preparation, (2013).

[103] D. Stacchiola, S. Kaya, J. Weissenrieder, H. Kuhlenbeck, S. Shaikhutdinov, H.-J. Freund, M. Sierka, T.K. Todorova, J. Sauer, Synthesis and Structure of Ultrathin Aluminosilicate Films, Angew. Chem. Int. Ed., 45 (2006) 7636-7639.

[104] J.A. Boscoboinik, X. Yu, B. Yang, F.D. Fischer, R. Włodarczyk, M. Sierka, S. Shaikhutdinov, J. Sauer, H.-J. Freund, Modeling Zeolites with Metal-Supported TwoDimensional Aluminosilicate Films, Angew. Chem. Int. Ed., 51 (2012) 6005-6008.

[105] A. Boscoboinik, X. Yu, B. Yang, S. Shaikhutdinov, H.-J. Freund, Building Blocks of Zeolites on an Aluminosilicate Ultra-Thin Film, Microporous Mesoporous Mater., 165 (2013) 158-162.

[106] Zeolites and Catalysis: Synthesis, Reactions and Applications, Wiley-VCH Verlag GmbH \& Co. KGaA, 2010.

[107] A. Boscoboinik, X. Yu, E. Emmez, B. Yang, S. Shaikhutdinov, F.D. Fischer, J. Sauer, H.-J. Freund, The interaction of probe molecules with bridging hydroxyls of twodimensional zeolites: a surface science approach, J. Phys. Chem. C, submitted (2013).

[108] B. Yoshiki, K. Matsumoto, High-Temperature Modification of Barium Feldspar, J. Am. Ceram. Soc., 34 (1951) 283-286. 


\section{Figure Captions:}

Fig. 1. Scanning Tunneling Microscopic images of Pd deposited on a thin alumina film at low (left) and high /right) resolution [4].

Fig. 2. Average hydrogenation rates on $\mathrm{Pd} / \mathrm{Fe}_{3} \mathrm{O}_{4}(111) / \mathrm{Pt}(111)$ model catalyst, in comparison to a $\mathrm{Pd}(111)$ single crystal. The panel shows the situation for the model catalysts without pre-deposition of carbon on the left and after carbon deposition on the right [17].

Fig. 3. The hydrogenation rates of cis-2-butene at $260 \mathrm{~K}$ over initially $\mathrm{D}_{2}$-saturated a) clean and b)carbon-precovered $\mathrm{Pd} / \mathrm{Fe}_{3} \mathrm{O}_{4}(111)$ model catalysts [17]. The cartoons on the right indicate how we envision carbon decoration on the edges of the Pd particle.

Fig. 4. Initial adsorption energies (I.e. at lowest coverage) for $\mathrm{O}_{2}$ (a) and $\mathrm{CO}$ (b) molecules plotted as a function of the nominal thickness of the deposited $\mathrm{Pd}$. The sizes are given as determined from STM measurements on $\mathrm{Pd} / \mathrm{Fe}_{3} \mathrm{O}_{4}(111) / \mathrm{Pt}(111)$ model catalysts in comparison to adsorption energies on $\mathrm{Pd}(111)$. Error bars show the standard of the mean of several measurements.

Fig. 5. STM images and height profiles (right panel) of $\mathrm{Au}$ islands grown on $\mathrm{MgO}(100)$ films of two thicknesses (as indicated in monolayers, ML). The oxide films have been grown on a $\mathrm{Ag}(001)$ surface.

Fig. 6. Schematic representation of the charge transfer process from the metal substrate through the thin oxide film to an adsorbed Au atom [54,60].

Fig. 7. STM images of $A u$ atoms adsorbed on a thin (3ML) MgO film on $\mathrm{Ag}(100)$ in comparison to Pd atoms adsorbed on the same supports [57].

Fig. 8. STM images of Au islands on thick pristine (left) and Mo doped $\mathrm{CaO}(100)$ films (right). The small insets show the higher resolution [64].

Fig. 9. STM typographic images of $0.5 \mathrm{ML}$ deposited onto a) $50 \mathrm{ML}$ thick Cao without dopants, b) Mo doped $\mathrm{CaO}$ films of $25 \mathrm{ML}$ in UHV and e)-f) in increasing $\mathrm{O}_{2}$ partial pressures from $5 \times 10^{-8}-2 \times 10^{-5} \mathrm{mbar}[23]$.

Fig. 10. Histograms of Au particle shapes for growth conditions identical to the ones in Fig. 9 a)-e). f) shows the number densities of $2 \mathrm{D}$ and $3 \mathrm{D}$ deposits as a function of the $\mathrm{O}_{2}$ background pressure during deposition [23].

Fig. 11. STM image of Pt nano particles on $\mathrm{Fe}_{3} \mathrm{O}_{4}(111)$. The inset shows an image with atomic resolution taken on the top facet of one of the Pt particles.

Fig. 12. STM image of the active tri-layer iron oxide phase. The inset shows an image at higher resolution. The panels surrounding the image represent the individual steps in forming the active tri-layer phase starting from $\mathrm{FeO}(111) / \mathrm{Pt}(111)$ and its reaction with $\mathrm{CO}$ to form $\mathrm{CO}_{2}$, as revealed by DFT calculations $[78,85,86]$.

Fig. 13. A 32 amu $\left(\mathrm{O}_{2}\right)$ signal in thermal desorption spectra of ultrathin oxide films grown on $\mathrm{Pt}(111)$ and exposed to $20 \mathrm{mbar}_{2}$ at $450 \mathrm{~K}$ for $10 \mathrm{~min}$. Data for a "native" Ru oxide films (RuO*) grown on $\mathrm{Ru}(0001)$ are shown for comparison. 
Fig. 14. Schematic structures a) of the $\mathrm{SiO}_{2,5}$ monolayer and b) the $\mathrm{SiO}_{2}$ double-layer on $\mathrm{Ru}(0001)$ as derived from DFT calculations. Both, the top and the side views are presented. Below the experimental IRAS spectra of the two systems are shown for comparison [100].

Fig. 15. (a, $f$ ) Zachariasen's schemes for the atomic arrangements of crystal (a) and a glass ( $f$ ) form [101]. (b, c, g, h) Atomically resolved crystalline and vitreous regions of the thin silica film (the scan area of these images is $3.5 \mathrm{~nm} \times 2.4 \mathrm{~nm}$ ). Green balls represent the assigned position of $\mathrm{Si}$ atoms, red balls for $\mathrm{O}$ atoms. (b) STM image of a crystalline area showing the position of $\mathrm{Si}$ atoms $\left(\mathrm{V}_{\mathrm{S}}=3.0 \mathrm{mV}, \mathrm{I}_{\mathrm{T}}=100 \mathrm{pA}\right)$. (c) STM image of a crystal line patch showing the arrangement of $\mathrm{O}$ atoms $\left(\left(\mathrm{V}_{\mathrm{S}}=100 \mathrm{mV}, \mathrm{I}_{\mathrm{T}}=100 \mathrm{pA}\right)\right.$. (g) STM image of a vitreous area revealing the positions of Si atoms $\left(\left(\mathrm{V}_{S}=2.0 \mathrm{~V}, \mathrm{I}_{\mathrm{T}}=50 \mathrm{pA}\right)\right.$. (h) STM image of a vitreous area showing the arrangement of $O$ atoms $\left(V_{S}=1000 \mathrm{mV}, I_{T}=100 p A\right)$ [97]. In (d,e,i,j) STM images of sample preparations with adsorbed metal particles are shown (scan size of $5.3 \mathrm{~nm} \times 3.3$ $\left.\mathrm{nm}, \mathrm{V}_{\mathrm{S}}=2 \mathrm{~V}, \mathrm{I}_{\mathrm{T}}=100 \mathrm{pA}\right)$. A direct comparison between $\mathrm{Au}(\mathrm{d}, \mathrm{i})$ and $\mathrm{Pd}(\mathrm{e}, \mathrm{j})$ adsorbed on freshly prepared silica films with cut-outs of crystalline $(d, e)$ and vitreous $(i, j)$ patches is provided [102].

Fig. 16. IRAS difference spectra taken on a hydrogenated alumino-silicate double layer as schematically shown in the inset. Upper trace: after H-D exchange, second trace: CO adsorption on the hydrogenated surface, lowest trace: after adsorption of ammonia on the hydrogenated surface $[104,107]$.

Fig. 17. STM image showing the morphology of the surface. Insets a), b) and c) correspond to regions containing $d 6 r, d 4 r+d 8 r$ and $d 5 r+d 7 r$, respectively. Red dots show the location of 0 atoms while the green atoms represent the tetrahedrally coordinated atoms. Insets $a^{\prime}, b^{\prime}, c^{\prime}$ show a different representation where the dots correspond to the location of the tetrahedrally coordinated atoms [104]. 